\title{
(2) OPEN ACCESS \\ Primary and secondary non-response: in need of operational definitions in observational studies
}

\author{
Enriqueta Vallejo-Yagüe (ㄷ, , ${ }^{1}$ Edward C Keystone, ${ }^{2}$ Sreemanjari Kandhasamy, ${ }^{1}$ \\ Raphael Micheroli (1), ${ }^{3}$ Axel Finckh 주, ${ }^{4}$ Andrea Michelle Burden (i) ${ }^{1}$
}

\section{Handling editor Josef $S$ Smolen}

'Department of Chemistry and Applied Biosciences, Institute of Pharmaceutical Sciences, ETH

Zürich, Zurich, Switzerland ${ }^{2}$ Faculty of Medicine, University of Toronto, Toronto, Ontario,

Canada

${ }^{3}$ Department of Rheumatology, University Hospital of Zurich, Zurich, Switzerland

${ }^{4}$ Division of Rheumatology, University Hospitals of Geneva, Geneva, Switzerland

\section{Correspondence to}

Professor Andrea Michelle

Burden, Department of

Chemistry and Applied

Biosciences, Institute of

Pharmaceutical Sciences, ETH

Zurich, Zurich CH-8093,

Switzerland:

andrea.burden@pharma.ethz.ch

Received 19 February 2021

Revised 6 April 2021

Accepted 8 April 2021

Published Online First

21 April 2021

\section{Check for updates}

(c) Author(s) (or their employer(s)) 2021. Re-use permitted under CC BY-NC. No commercial re-use. See rights and permissions. Published by BMJ.

To cite: Vallejo-Yagüe $\mathrm{E}$ Keystone EC, Kandhasamy S, et al. Ann Rheum Dis 2021:80:961-964.

\section{INTRODUCTION}

Treatment response to biologics and targeted synthetic disease-modifying antirheumatic drugs in rheumatoid arthritis (RA) patients can be classified as primary or secondary non-response, based on evidence of an initial response. Conceptually, primary non-response is generally considered if the drug was ineffective, with no clinical response within the initial treatment period, while secondary non-response would be considered if, after an initial response, the effectiveness is lost over time. ${ }^{1-4}$ Despite these generally accepted definitions, there is no consensus on how to operationalise these concepts. Consequently, the current observational evidence is highly heterogeneous and the prevalence of primary versus secondary failure remains largely unknown.

The underlying mechanisms for primary and secondary non-response may differ, ${ }^{3}{ }^{5}$ thus, we believe that defining the type of non-response is key to improving patient care. While primary non-response may be due to a mechanistic failure, secondary non-response may be driven by immunogenicity. Previous studies have shown that both the type of non-response and the development of antidrug antibodies (ADAbs) are important factors when predicting the success of the second biologic. ${ }^{67}$ Thus, developing clear definitions of how to operationalise primary and secondary nonresponse is essential to accelerate research that aims to predict the optimal therapy for a given patient, ${ }^{5}$ which will, in turn, improve clinical practice recommendations. For example, if a patient is a primary non-responder to a tumour necrosis factor inhibitor (anti-TNF), the best practice would likely be to switch to a biologic with different mechanism of action. However, if the patient was able to achieve clinical response prior to failure (secondary nonresponder), it would be reasonable to proceed with another anti-TNF. Additionally, following the growing postmarketing research targeting comparative effectiveness of treatments in RA, agreement on operational definitions would improve cross-study comparisons. Thus, we believe that unifying this terminology would benefit the clinical practice, clinical trials and postmarketing research, and a unique operational procedure for those three scenarios would be ideal. However, since translating clinical concepts into studies in real-world data represents extra challenges, we drive our discussion in the context of observational research.

In this viewpoint, we discuss the concepts of primary and secondary non-response, with special attention to its implementation in observational data, and we suggest recommendations for future research. Ultimately, we hope this discussion will trigger expert committees to develop standard terminology for these concepts as a step towards harmonising study results.

\section{CONCEPTUAL CHALLENGES}

Despite the limited publications distinguishing between primary and secondary non-response, a common method used in observational studies consists on establishing a time point to assess primary response using composite disease activity scores. Once primary response is achieved, maintenance or deterioration of the disease status can be studied by assessing disease activity at later time points. ${ }^{8-12}$ While some publications use a 3 -month time point, ${ }^{811}$ there is high tendency to identify primary response within the first 6 months. ${ }^{241012}$ The European Alliance of Associations for Rheumatology (EULAR) recommends to switch biological treatment if at 3 months there is no improvement and at 6 months the target (low disease activity or remission) has not been reached. ${ }^{13}$ In observational studies using registry data, not all patients have recorded visits with the same frequency, and visits with complete information may be restricted to a year and/or half-year visit (and occasionally longer periods). This can result in missing data on measurements to quantify treatment response, especially when assessing short time periods, such as 3 months. Thus, 6 months is likely ideal to aid with limitations intrinsic to real-world data, while remaining in-line with clinical guidelines.

While assessing primary response at 6 months is straightforward and generally accepted, there is less agreement on how, or when, to define secondary non-response. For example, what evidence of an initial response is needed, and for how long should this response be held? These questions are pivotal for determining if patients who quickly lose their response belong to the same category as those who relapse after a period of evidenced sustained response. We argue here, that there may be important differences, and therefore, conceptualising these patients as different categories seems reasonable. Following this argument, one may consider that maintaining evidenced positive effect for a period of $\geq 12$ months from treatment initiation, or having two consecutive positive measurements with a minimum time interval, could be understood as clinically relevant sustained response. This leaves a period between 6 and 12 months that may require specific characterisation. Thus, we 


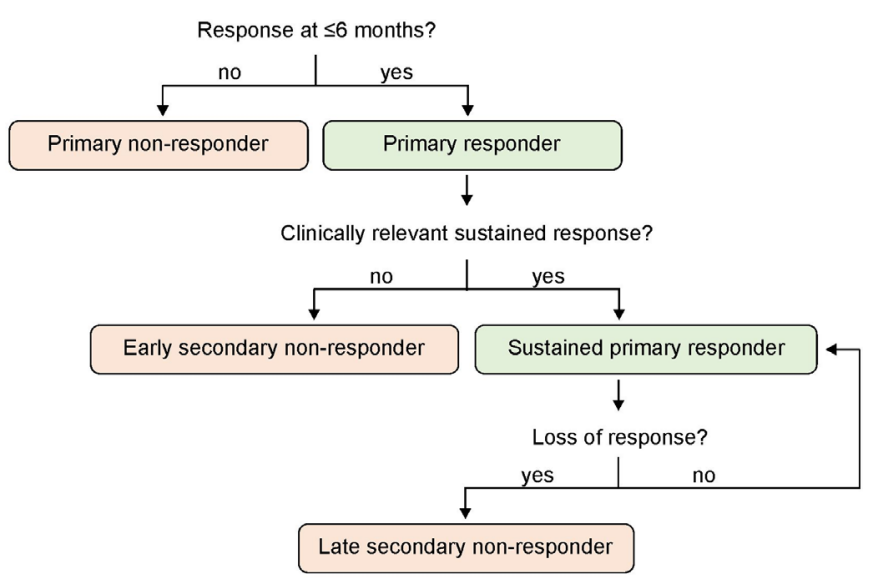

Figure 1 Decision tree to classify treatment response to biologics and targeted synthetic disease-modifying antirhematic drugs in rheumatoid arthritis based on evidence of an initial response, assuming a clinically relevant sustained response as prerequisite prior late secondary nonresponse. Patients discontinuing treatment due to remission or safety reasons are not reflected in the decision tree.

identify three response categories of interest, and propose the following three-level classification to differentiate response:

- Primary non-response: Lack of response within the first 6 months of treatment.

- Early secondary non-response: Primary response followed by failure to maintain a positive effectiveness outcome for at least 12 months from treatment initiation or to achieve two consecutive positive measurements with a minimum time interval.

- Late secondary non-response: Loss of response after having sustained a positive effectiveness outcome for $\geq 12$ months from treatment initiation, or after two consecutive positive measurements with a minimum time interval.

This conceptualisation is illustrated in figure 1. Additionally, five case examples of patient trajectories are presented in figure 2 . For instance, the second example in figure 2 represents a patient who is classified as primary responder based on the evidence of EULAR good response at 4 months ( $\leq 6$ months), however, this response is not sustained at 12 months and the patient does not have two consecutive successful response measures with minimal time interval, thus, the patient would therefore be classified as an early secondary non-responder.

While we propose a model based on researcher-defined primary and secondary non-response in observational data using timelines, alternative approaches could be used. For example, one approach may be to use physicians' judgement on primary and secondary non-response (ie, physician-reported reason for treatment stop/switch), if available. However, this will vary vastly based on the individual physician interpretation. In a study by Keystone et $a l,{ }^{4}$ there were discrepancies in the time periods of reported primary and secondary non-response between two Canadian registries, indicating a lack of consensus among physicians on the operational definitions. Thus, it is evident that there is significant need for work in this area. However, we acknowledge that if agreement on a more harmonised definition of primary and secondary non-response in clinical practice is achieved, this may be implemented in registries, hoping to improve the use of physician's reason for treatment discontinuation to study response. Alternatively, treatment discontinuation for non-safety related reasons within the above discussed time frames may be an option to assess response if effectiveness instruments are missing in the data.

\section{OVERVIEW AND NEXT STEPS}

The underlying mechanisms for treatment failure may differ between patients with primary non-response and patients in whom effectiveness is lost over time. ${ }^{35}$ Additionally, the type of response may help treatment decision making. ${ }^{5}$ This supports the need for standard definitions of primary and secondary non-response, and reflects important considerations for driving our operational definitions. While there is a general consensus to identify primary response within the first 6 months of treatment, ${ }^{2410} 12$ there is no agreement on how to assess secondary non-response. Additionally, it remains unclear if patients losing the effectiveness of a treatment after a brief response are similar to those losing it after a sustained beneficial effect. Thus, as outlined above, in addition to the primary non-response, we recommend considering two categories for secondary non-response (early vs late), and we described an approach for assessing the type of response based on timelines.

While the use of timelines may be subject to potential misclassification (eg, if comedication with steroids blurs measurements of response), time frames are often used to assess treatment response and it would mean an easy transition from current standards. In the future, alternative datadriven (machine learning) strategies and therapeutic drug monitoring studies identifying ADAb levels may be used to complement the proposed approach. However, until further research is completed, the proposed classification and timelines can provide a guidance to improve the transparency and homogeneity in research.

Standardising the terminology of primary and secondary non-response is common to all aspects of rheumatology research (observational and interventional). Thus, unifying this terminology will benefit the clinical practice, clinical trials and postmarketing research. Here, we focused on observational research due to the complexity of using secondary data, such as disease or biological registries. While these data include detailed information on rheumatic treatment and diseasespecific variables, enabling assessment of disease progression, ${ }^{14}$ data on ADAbs may be lacking and loss to follow-up present significant challenges. We acknowledge that due to the great heterogeneity between data sources (eg, different composite disease activity scores) and treatments (eg, rituximab), a single operational definition of primary and secondary non-response in observational studies may be unrealistic. However, there are some common methodological approaches, particularly related to timing of measurement and categorisation terminology.

Thus, while there are remaining challenges in developing standard terminology and operational definitions of primary and secondary non-response, we believe expert-driven guidelines from organisms such as EULAR, the American College of Rheumatology, or Outcomes Measures in Rheumatology, would be a beneficial step forward. Additionally, data-driven approaches and further evidence from therapeutic drug monitoring studies on immunogenicity will contribute to guideline development as it becomes available. However, until consensus is reached, we urge researchers to improve clarity in the reported methodology, particularly on the timing of how non-response was measured in observational studies in order to improve cross-study comparisons between those with similar outcome definitions. 
Example 1 - Primary non-response

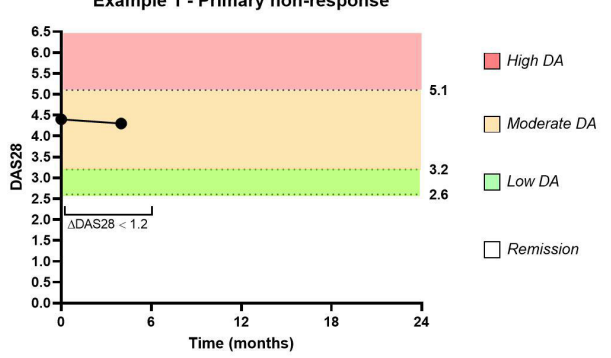

Example 3 - Primary response, sustained

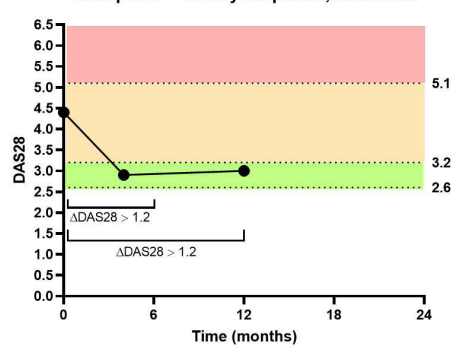

$\square$ High DA

$\square$ Moderate DA

$\square$ Low $D A$

$\square$ Remission
Example 2 - Early secondary non-response
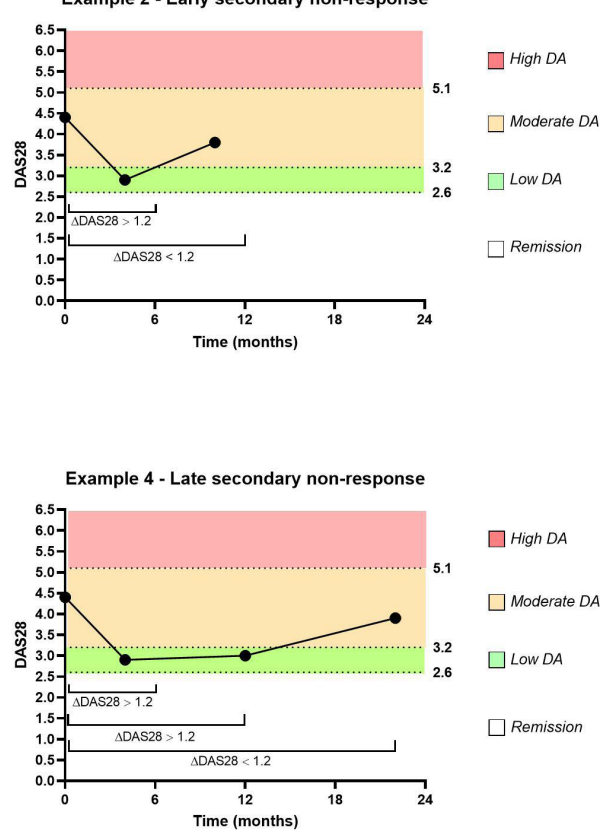

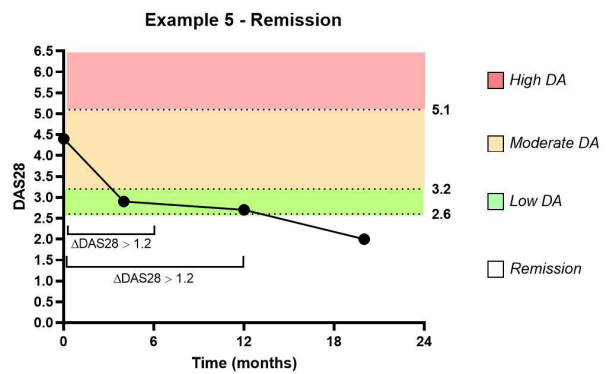

Figure 2 Examples of patient trajectory of treatment response for studies on rheumatoid arthritis patients in real-world data registries. Response as per European Alliance of Associations for Rheumatology (EULAR) good response, defined as Disease Activity Score 28 (DAS28) change $>1.2$ with achieved DAS28 $\leq 3.2$. Example one does not achieve response at $\leq 6$ months, representing a primary non-responder. Examples $2-5$ are primary responders, with response to treatment at $\leq 6$ months. In example 2, despite primary response, the effectiveness is lost before the 12 month time point, thus, the patient classifies as early secondary non-responder. Examples 3 and 4 have sustained response for at least 12 months, or had two consecutive positive measurements at $\leq 12$ months. Once achieved sustained response, example four loses it over time, characterising as late secondary non-responder. Example five eventually ends in remission (DAS28 <2.6).

Correction notice This article has been corrected since it published Online First. The expansion for EULAR has been correction.

Twitter Andrea Michelle Burden @ETH_PharmEpi

Contributors EV-Y and AMB wrote the manuscript. EV-Y and SK performed background research. All authors provided input, and read and approved the final manuscript.

Funding The authors have not declared a specific grant for this research from any funding agency in the public, commercial or not-for-profit sectors.

Competing interests ECK: Speakers bureau from Amgen, AbbVie, F. HoffmannLa Roche, Janssen, Merck, Novartis, Pfizer Pharmaceuticals, Sanofi Genzyme; and consultant of AbbVie, Amgen, Bristol-Myers Squibb Company, Celltrion, Myriad Autoimmune, F. Hoffmann-La Roche Inc, Gilead, Janssen, Lilly Pharmaceuticals, Merck, Pfizer Pharmaceuticals, Sandoz, Sanofi-Genzyme, Samsung Bioepsis; and grant/research support from Amgen, Merck, Pfizer Pharmaceuticals, PuraPharm. RM: Consultant of Gilead, Eli-Lilly, Pfizer and Abbvie. AF: Speakers bureau from Pfizer, Eli-Lilly; and consultant of AbbVie, BMS, Gilead, Novartis, Pfizer, Viatris; and grant/ research support from Pfizer, BMS.

Patient and public involvement Patients and/or the public were not involved in the design, or conduct, or reporting, or dissemination plans of this research.

Patient consent for publication Not required.

Provenance and peer review Not commissioned; externally peer reviewed.
Open access This is an open access article distributed in accordance with the Creative Commons Attribution Non Commercial (CC BY-NC 4.0) license, which permits others to distribute, remix, adapt, build upon this work non-commercially, and license their derivative works on different terms, provided the original work is properly cited, appropriate credit is given, any changes made indicated, and the use is non-commercial. See: http://creativecommons.org/licenses/by-nc/4.0/.

\section{ORCID iDs}

Enriqueta Vallejo-Yagüe http://orcid.org/0000-0002-5911-2037

Raphael Micheroli http://orcid.org/0000-0002-8918-7304

Axel Finckh http://orcid.org/0000-0002-1210-4347

Andrea Michelle Burden http://orcid.org/0000-0001-7082-8530

\section{REFERENCES}

1 Rubbert-Roth A, Finckh A. Treatment options in patients with rheumatoid arthritis failing initial TNF inhibitor therapy: a critical review. Arthritis Res Ther 2009;11 Suppl 1:S1.

2 Youssef $\mathrm{P}$, Marcal B, Button P, et al. Reasons for biologic and targeted synthetic disease-modifying antirheumatic drug cessation and persistence of second-line treatment in a rheumatoid arthritis dataset. J Rheumato/ 2020;47:1174-81.

3 Wijbrandts CA, Tak PP. Prediction of response to targeted treatment in rheumatoid arthritis. Mayo Clin Proc 2017;92:1129-43. 
4 Keystone EC, Rampakakis E, Movahedi M, et al. Toward defining primary and secondary nonresponse in rheumatoid arthritis patients treated with anti-TNF: results from the BioTRAC and OBRI registries. J Rheumatol 2020;47:510-7.

5 Tak PP. A personalized medicine approach to biologic treatment of rheumatoid arthritis: a preliminary treatment algorithm. Rheumatology 2012;51:600-9.

6 Jamnitski A, Bartelds GM, Nurmohamed MT, et al. The presence or absence of antibodies to infliximab or adalimumab determines the outcome of switching to etanercept. Ann Rheum Dis 2011;70:284-8.

7 Singh S, George J, Boland BS, et al. Primary non-response to tumor necrosis factor antagonists is associated with inferior response to second-line biologics in patients with inflammatory bowel diseases: a systematic review and meta-analysis. J Crohns Colitis 2018;12:635-43.

8 Virkki LM, Valleala H, Takakubo Y, et al. Outcomes of switching anti-TNF drugs in rheumatoid arthritis - a study based on observational data from the Finnish register of biological treatment (ROB-FIN). Clin Rheumatol 2011;30:1447-54.

9 Wick MC, Ernestam S, Lindblad S, et al. Adalimumab (Humira $\left.{ }^{\circledR}\right)$ restores clinical response in patients with secondary loss of efficacy from infliximab (Remicade $®$ ) or etanercept (Enbrelß): results from the STURE registry at Karolinska university hospital. Scand J Rheumatol 2005;34:353-8.

10 Lequerré T, Farran Émilie, Ménard J-F, et al. Switching from an anti-TNF monoclonal antibody to soluble TNF-receptor yields better results than vice versa: An observational retrospective study of 72 rheumatoid arthritis switchers. Joint Bone Spine 2015;82:330-7.

11 Buch MH, Bingham SJ, Bryer D, et al. Long-Term infliximab treatment in rheumatoid arthritis: subsequent outcome of initial responders. Rheumatology 2007;46:1153-6.

12 Pettipher $C$, Rudolph $R$, Musenge $E$, et al. A prospective study of anti-tumor necrosis factor therapy in South African rheumatoid arthritis patients. Int J Rheum Dis 2016;19:594-9.

13 Smolen JS, Landewé RBM, Bijlsma JWJ. EULAR recommendations for the management of rheumatoid arthritis with synthetic and biological disease-modifying antirheumatic drugs: 2019 update. Ann Rheum Dis 2020;79:685-99.

14 Nikiphorou E, Buch MH, Hyrich KL. Biologics registers in RA: methodological aspects, current role and future applications. Nat Rev Rheumatol 2017;13:503-10. 